\title{
Adjuvants and Antigen-Delivery Systems for Subunit Vaccines against Tuberculosis
}

\author{
Abu Salim Mustafa
}

check for

Citation: Mustafa, A.S. Adjuvants and Antigen-Delivery Systems for Subunit Vaccines against

Tuberculosis. Vaccines 2021, 9, 972. https://doi.org/10.3390/vaccines 9090972

Received: 19 August 2021

Accepted: 20 August 2021

Published: 30 August 2021

Publisher's Note: MDPI stays neutral with regard to jurisdictional claims in published maps and institutional affiliations.

Copyright: (C) 2021 by the author. Licensee MDPI, Basel, Switzerland. This article is an open access article distributed under the terms and conditions of the Creative Commons Attribution (CC BY) license (https:// creativecommons.org/licenses/by/ $4.0 /)$.
Department of Microbiology, Faculty of Medicine, Kuwait University, Safat 13110, Kuwait; abu.mustafa@ku.edu.kw; Tel.: +965-2463-6505

\begin{abstract}
The only licensed vaccine against tuberculosis is BCG. However, BCG has failed to provide consistent protection against tuberculosis, especially pulmonary disease in adults. Furthermore, the use of BCG is contraindicated in immunocompromised subjects. The research towards the development of new vaccines against TB includes the use of Mycobacterium tuberculosis antigens as subunit vaccines. Such vaccines may be used either alone or in the prime-boost model in BCGvaccinated people. However, the antigens for subunit vaccines require adjuvants and/or delivery systems to induce appropriate and protective immune responses against tuberculosis and other diseases. Articles published in this Special Issue have studied the pathogenesis of BCG in children and the use of BCG and recombinant BCG as potential vaccines against asthma. Furthermore, the use of different adjuvants and delivery systems in inducing the protective immune responses after immunization with subunit vaccines has been described.
\end{abstract}

Keywords: tuberculosis; subunit vaccines; antigens; adjuvants; delivery systems

Tuberculosis (TB) is a global infectious disease that has been known to humans since ancient times. Although, various steps to control TB have been undertaken by different governments, as well as the World Health Organization, TB remains among the top 10 diseases in the world [1]. According to the most recent estimates from the World Health Organization, 10 million people developed the active disease, and 1.4 million people died of TB in 2019 [2]. The only licensed vaccine currently used against TB is the bacillus Calmette Guerin (BCG), which was obtained upon the attenuation of the pathogenic Mycobacterium bovis after subculturing on artificial medium for 13 years (1908-1921) and 231 passages [3]. In 1974, the World Health Organization included BCG in its list of vaccines recommended for the Expanded Program on Immunization [4]. Currently, BCG is administered to more than 100 million neonates per year and provides about $50 \%$ protection against clinical TB in children [5]. However, BCG is a live vaccine, and its administration leads to infection in about 1:10,000 to 1:1,000,000 children [6]. In this Special Issue of Vaccines, invited experts have contributed articles related to the pathogenesis of BCG in neonates, the protective potential of BCG against asthma, and the use of mycobacterial antigens as subunit vaccines in inducing protective immune responses by using different adjuvants and delivery systems.

The article by Al Busaidi et al. reports the spectrum of BCG-induced disease among children in Oman [7]. They included all children of $<14$ years of age who had laboratoryconfirmed BCG disease from January 2006 to December 2018. The results of the study showed that 9.2 cases of BCG disease occurred in 100,000 vaccinated neonates. Children with immunodeficiency and those presenting the symptoms within 6 month of vaccination had more severe and disseminated disease. The age of disease presentation and the severity of BCG diseases were significantly associated with immunodeficiency status [7].

The BCG vaccine has also been reported to protect against other mycobacterial diseases (leprosy and non-tuberculous mycobacterial infections) [8] and non-mycobacterial diseases, including allergic diseases, such as asthma, and different types of cancers [9-11]. Allergic 
asthma is characterized by the secretion of antigen-specific T helper 2 (Th2) cytokines (e.g., IL-5 and IL-13) in large quantities [12]. On the other hand, the cytokines IFN- $\gamma$ and IL-10 secreted by Th1 and T regulatory (Treg) cells, respectively, are associated with protection against asthma [13]. In mice, injection with BCG has been demonstrated to suppresses allergen-induced airway eosinophilia (a hallmark of allergic asthma), along with decreased production of Th-2 cytokine IL-5 and shifting the immune balance towards Th- 1 cytokines in bronchoalveolar lavage fluid [14]. It has been further shown that recombinant BCG secreting murine IL-18 (rBCG-mIL-18) further increases Th- 1 cytokine production in mice [15]. In the ovalbumin-induced murine model of asthma, $r B C G-m I L-18$ protected mice better than wild-type BCG against allergen-induced eosinophilia and IL-5 production [16]. Furthermore, it has been shown in humans that, compared to wild-type BCG, a recombinant BCG strain secreting human IL-18 (rBCG-hIL-18) induced stronger IFN- $\gamma$ production by $\mathrm{T}$ cells cocultured with dendritic cells (DCs) from healthy BCG-vaccinated subjects [17]. In the article published by Kowalewicz-Kulbat et al. in this Special Issue, the authors have shown that in the presence of a major allergen of house dust mites (Der p 1), BCGand rBCG-hIL-18-pulsed monocyte-derived dendritic cells (MD-DCs) co-cultured with naïve $T$ cells from allergic patients resulted in a decrease in IL-5 production compared to non-pulsed MD-DCs cultured in the presence of Der $\mathrm{p} 1$ alone. [18]. Based on these results, the authors suggest that BCG, and especially rBCG-hIL-18, may have therapeutic value in reducing the exacerbated $\mathrm{Th} 2$ responses in patients with allergic asthma.

BCG has been used as a vaccine to protect against TB since 1921, but it has failed to provide consistent protection in different parts of the world, especially against pulmonary TB in adults [9]. Furthermore, BCG can cause disseminated disease in immunocompromised individuals [19]. Hence, more effective and safer vaccines are required to protect against TB. Among the approaches towards the development of new vaccines against TB is the use of Mycobacterium tuberculosis antigens as subunit vaccines [20]. Such vaccines may be used either alone as priming vaccines or in a prime-boost model in BCG-vaccinated people. However, the antigens for subunit vaccines will require adjuvants and/or delivery systems to induce appropriate and protective immune responses against TB [21,22].

In this Special Issue, the results of the adjuvant effects of the cytokine IL-7and transcriptional factors (Id3, Bcl6, Bach2, and Blimp1) in increasing the duration of the immune memory induced by tuberculosis subunit vaccines was studied in mice by Han et al. [23]. Groups of mice were immunized three times at two-week intervals with the M. tuberculosis subunit vaccine Mtb10.4-HspX (MH) plus ESAT6-Ag85B-MPT64 $<190-198>-\mathrm{Mtb} 8.4-\mathrm{Rv} 2626 \mathrm{c}$ (LT70), together with adeno-associated virus-mediated IL-7 or lentivirus-mediated transcriptional factor Id3, Bcl6, Bach2, and Blimp1. The vaccine-induced immune responses were evaluated at 25 weeks after the last immunization. The results showed that IL-7 plus the TB subunit vaccine induced the formation of long-lived memory $\mathrm{T}$ cells and increased the expression of $I d 3, B c l 6$, and bach2, which are the three main transcription factors involved in the generation of long-lived memory $\mathrm{T}$ cells. The results of immunization with the transcriptional factors along with the subunit vaccines showed that Bcl6 and Id3 resulted in the increased production of antigen-specific antibodies and long-lived memory $\mathrm{T}$ cells. These results showed that IL-7 and transcriptional factors Id 3 and Bcl6 acted as adjuvants in helping the TB subunit vaccine to induce long-term immune memory, which plays a role in providing protection against $M$. tuberculosis infection.

Many other adjuvants and delivery systems have been used to improve the protective immune responses induced by subunit vaccines against TB, which include bacterial and viral vectors, liposomes, nanoparticles, plasmid DNA, and edible-based strategies, etc. [24-26]. A large number of such vaccines have been tested in animal models of TB with encouraging results [24-26]. Some of these subunit vaccines using various antigens, adjuvants, and delivery systems have reached Phase I and/or Phase II clinical trials in humans (Table 1). 
Table 1. Adjuvants and delivery systems used with subunit vaccines undergoing clinical trials in humans.

\begin{tabular}{|c|c|c|c|}
\hline Subunit Vaccine Antigens & Adjuvant ${ }^{a} /$ Delivery System ${ }^{b}$ & Vaccine Designation & Reference \\
\hline Rv2608, Rv3619c, Rv3620c, Rv1813 & GLA-SE & ID93/GLA-SE & [27-29] \\
\hline Ag85B, ESAT6 & IC31 & H1:IC31 & {$[30,31]$} \\
\hline Ag85B, ESAT6, Rv2660c & IC31 & H56:IC31 & {$[32,33]$} \\
\hline Ag85B, TB10.4 & IC31 & H4:IC31/AERAS 404 & [34-36] \\
\hline Mtb32A, Mtb39A & AS01 $1_{\mathrm{E}}$ & $\mathrm{M} 72 / \mathrm{ASO1}_{\mathrm{E}}$ & {$[37,38]$} \\
\hline Ag85b, ESAT6, CFP10 & CpG and aluminum salt & $\mathrm{AEC} / \mathrm{BC} 02$ & [39] \\
\hline Ag85B, ESAT6, CFP10 & BCG & Gam TBvac & {$[36,40]$} \\
\hline Ag85A, Ag85B, TB10.4 & Ad35 & AERAS-402 & [41] \\
\hline Ag85A & MVA & MVA85A & [42] \\
\hline Ag85A & MVA, ChAdOx1 & MVA85A, ChAdOx1 85A & [43] \\
\hline Ag85A, ESAT6 & Flu-04L & TB/Flu-04L & [36] \\
\hline
\end{tabular}

${ }^{\text {a }}$ Adjuvants $=$ GLA-SE, IC31, AS01 ${ }_{\mathrm{E}}, \mathrm{CpG}$ and aluminum salt. ${ }^{\mathrm{b}}$ Delivery system = BCG, Ad35, MVA, ChAdOx1, Flu-04L.

The subunit vaccines listed in Table 1 have been shown to be safe in humans and induce appropriate immune responses correlating with protective potential.

In conclusion, the use of appropriate adjuvants and delivery systems for tuberculosis subunit vaccines has gone beyond the experiments in animals and several clinical trials in humans have been conducted with satisfactory outcomes. These results provide hope for new TB vaccines that may have a safety profile better than the currently used BCG vaccine. Furthermore, such subunit vaccines may be able to replace BCG or can be used as boosters in BCG-vaccinated subjects in prime-boost strategies.

Funding: This research was funded by Kuwait University, Research Sector grant nos. MI02/12, SRUL02/13, and GM01/15.

Institutional Review Board Statement: Not applicable.

Informed Consent Statement: Not applicable.

Conflicts of Interest: The author declares no conflict of interest.

\section{References}

1. World Health Organization. Multisectorial Accountability Framework to Accelerate Progress to End Tuberculosis by 2030.2019. Available online: https://www.who.int/tb/WHO_Multisectoral_Framework_web.pdf (accessed on 15 August 2021).

2. World Health Organization. Global Tuberculosis Report 2020. Available online: https://www.who.int/publications/i/item/97 89240013131 (accessed on 16 August 2021).

3. Mustafa, A.S. BCG pros and cons and new/improved vaccines for tuberculosis. In Text Book of Biochemistry, Biotechnology, Allied and Molecular Medicine, 4th ed.; Talwar, G.P., Hasnain, S.E., Sarin, S.K., Eds.; PHI Learning Private Limited: Delhi, India, 2016; pp. 1347-1353.

4. BCG Vaccines. 2017. Available online: https://www.who.int/immunization/sage/meetings/2017/october/1_BCG_report_ revised_version_online.pdf?ua=1 (accessed on 16 August 2021).

5. Syggelou, A.; Spyridis, N.; Benetatou, K.; Kourkouni, E.; Kourlaba, G.; Tsagaraki, M.; Maritsi, D.; Eleftheriou, I.; Tsolia, M. BCG vaccine protection against TB Infection among children older than 5 Years in close contact with an infectious adult TB Case. J. Clin. Med. 2020, 9, 3224. [CrossRef]

6. Ying, W.; Sun, J.; Liu, D.; Hui, X.; Yu, Y.; Wang, J.; Wang, X. Clinical characteristics and immunogenetics of BCGosis/BCGitis in Chinese children: A 6 year follow-up study. PLoS ONE 2014, 9, e94485. [CrossRef] [PubMed]

7. Al Busaidi, N.; Kp, P.; Al-Jardani, A.; Al-Sukaiti, N.; Al Tamemi, S.; Al-Rawahi, B.; Al Hinai, Z.; Alyaquobi, F.; Al-Abri, S.; Al-Maani, A. The spectrum of Bacille Calmette-Guérin diseases in children-a decade of data from neonatal vaccination settings. Vaccines 2021, 9, 150. [CrossRef]

8. Zimmermann, P.; Finn, A.; Curtis, N. Does BCG Vaccination Protect Against Nontuberculous Mycobacterial Infection? A Systematic Review and Meta-Analysis. J. Infect. Dis. 2018, 218, 679-687. [CrossRef]

9. Ahmed, A.; Rakshit, S.; Adiga, V.; Dias, M.; Dwarkanath, P.; D’Souza, G.; Vyakarnam, A. A century of BCG: Impact on tuberculosis control and beyond. Immunol. Rev. 2021, 301, 98-121. [CrossRef]

10. Mustafa, A.S. BCG as a Vector for novel recombinant vaccines against infectious diseases and cancers. Vaccines $2020,8,736$. [CrossRef]

11. Mustafa, A.S. Vaccine Potential of Mycobacterial antigens against Asthma. Med. Princ. Pract. 2020, 29, 404-411. [CrossRef] 
12. Drick, N.; Seeliger, B.; Welte, T.; Fuge, J.; Suhling, H. Anti-IL-5 therapy in patients with severe eosinophilic asthma-Clinical efficacy and possible criteria for treatment response. BMC Pulm. Med. 2018, 18, 119. [CrossRef]

13. Ji, N.F.; Xie, Y.C.; Zhang, M.S.; Zhao, X.; Cheng, H.; Wang, H.; Arozena, A.C.; Adachi, H.; Adams, C.M.; Adams, P.D.; et al. Ligustrazine corrects Th1/Th2 and Treg/Th17 imbalance in a mouse asthma model. Int. Immunopharmacol. 2014, $21,76-81$. [CrossRef]

14. Erb, K.J.; Holloway, J.W.; Sobeck, A.; Moll, H.; Le Gros, G. Infection of Mice with Mycobacterium bovis-Bacillus Calmette-Guérin (BCG) Suppresses Allergen-induced Airway Eosinophilia. J. Exp. Med. 1998, 187, 561-569. [CrossRef]

15. Biet, F.; Kremer, L.; Wolowczuk, I.; Delacre, M.; Locht, C. Mycobacterium bovis BCG Producing Interleukin-18 Increases AntigenSpecific Gamma Interferon Production in Mice. Infect. Immun. 2002, 70, 6549-6557. [CrossRef]

16. Biet, F.; Duez, C.; Kremer, L.; Marquillies, P.; Amniai, L.; Tonnel, A.-B.; Locht, C.; Pestel, J. Recombinant Mycobacterium bovis BCG producing IL-18 reduces IL-5 production and bronchoalveolar eosinophilia induced by an allergic reaction. Allergy 2005, 60, 1065-1072. [CrossRef]

17. Szpakowski, P.; Biet, F.; Locht, C.; Paszkiewicz, M.; Rudnicka, W.; Druszczyńska, M.; Allain, F.; Fol, M.; Pestel, J.; KowalewiczKulbat, M. Dendritic Cell Activity Driven by Recombinant Mycobacterium bovis BCG Producing Human IL-18, in Healthy BCG Vaccinated Adults. J. Immunol. Res. 2015, 2015, 1-13. [CrossRef]

18. Kowalewicz-Kulbat, M.; Szpakowski, P.; Krawczyk, K.T.; Kowalski, M.L.; Kosinski, S.; Biet, F.; Rudnicka, W.; Locht, C. Decrease of IL-5 Production by Naive T Cells Cocultured with IL-18-Producing BCG-Pulsed Dendritic Cells from Patients Allergic to House Dust Mite. Vaccines 2021, 9, 277. [CrossRef]

19. Dockrell, H.M.; Smith, S.G. What Have We Learnt about BCG Vaccination in the Last 20 Years? Front. Immunol. 2017, 8, 1134. [CrossRef]

20. Mustafa, A.S. Vaccine potential of Mycobacterium tuberculosis-specific genomic regions: In vitro studies in humans. Expert Rev. Vaccines 2009, 8, 1309-1312. [CrossRef]

21. Safar, H.A.; Mustafa, A.S.; Amoudy, H.A.; El-Hashim, A. The effect of adjuvants and delivery systems on Th1, Th2, Th17 and Treg cytokine responses in mice immunized with Mycobacterium tuberculosis-specific proteins. PLoS ONE 2020, 15, e0228381. [CrossRef]

22. Franco, A.R.; Peri, F. Developing New Anti-Tuberculosis Vaccines: Focus on Adjuvants. Cells 2021, 10, 78. [CrossRef]

23. Han, J.; Ma, Y.; Ma, L.; Tan, D.; Niu, H.; Bai, C.; Mi, Y.; Xie, T.; Lv, W.; Wang, J.; et al. Id3 and Bcl6 Promote the Development of Long-Term Immune Memory Induced by Tuberculosis Subunit Vaccine. Vaccines 2021, 9, 126. [CrossRef]

24. Agger, E.M. Novel adjuvant formulations for delivery of anti-tuberculosis vaccine candidates. Adv. Drug Deliv. Rev. 2016, 102, 73-82. [CrossRef]

25. Stewart, E.; Triccas, J.A.; Petrovsky, N. Adjuvant Strategies for More Effective Tuberculosis Vaccine Immunity. Microorganisms 2019, 7, 255. [CrossRef] [PubMed]

26. Mustafa, A.S. Immunological characterization of proteins expressed by genes located in Mycobacterium tuberculosis-specific genomic regions encoding the ESAT6-like proteins. Vaccines 2021, 9, 27. [CrossRef] [PubMed]

27. Day, T.A.; Penn-Nicholson, A.; Luabeya, A.K.K.; Fiore-Gartland, A.; Du Plessis, N.; Loxton, A.G.; Vergara, J.; Rolf, T.A.; Reid, T.D.; Toefy, A.; et al. Safety and immunogenicity of the adjunct therapeutic vaccine ID93 + GLA-SE in adults who have completed treatment for tuberculosis: A randomised, double-blind, placebo-controlled, phase 2a trial. Lancet Respir. Med. 2021, 9, 373-386. [CrossRef]

28. Penn-Nicholson, A.; Tameris, M.; Smit, E.; Day, T.A.; Musvosvi, M.; Jayashankar, L.; Vergara, J.; Mabwe, S.; Bilek, N.; Geldenhuys, H.; et al. Safety and immunogenicity of the novel tuberculosis vaccine ID93 + GLA-SE in BCG-vaccinated healthy adults in South Africa: A randomised, double-blind, placebo-controlled phase 1 trial. Lancet Respir. Med. 2018, 6, 287-298. [CrossRef]

29. Coler, R.N.; Day, T.A.; Ellis, R.; Piazza, F.M.; Beckmann, A.M.; Vergara, J.; Rolf, T.; Lu, L.; Alter, G.; Hokey, D.; et al. The TLR-4 agonist adjuvant, GLA-SE, improves magnitude and quality of immune responses elicited by the ID93 tuberculosis vaccine: First-in-human trial. NPJ Vaccines 2018, 3, 34. [CrossRef]

30. Hussein, J.; Zewdie, M.; Yamuah, L.; Bedru, A.; Abebe, M.; Dagnew, A.F.; Chanyalew, M.; Yohannes, A.G.; Ahmed, J.; Engers, H.; et al. A phase I, open-label trial on the safety and immunogenicity of the adjuvanted tuberculosis subunit vaccine H1/IC31®in people living in a TB-endemic area. Trials 2018, 19, 24. [CrossRef] [PubMed]

31. Mearns, H.; Geldenhuys, H.D.; Kagina, B.M.; Musvosvi, M.; Little, F.; Ratangee, F.; Mahomed, H.; Hanekom, W.A.; Hoff, S.T.; Ruhwald, M.; et al. H1:IC31 vaccination is safe and induces long-lived TNF- $\alpha^{+}$IL-2 ${ }^{+}$CD4 T cell responses in M. tuberculosis infected and uninfected adolescents: A randomized trial. Vaccine 2017, 35, 132-141. [CrossRef] [PubMed]

32. Suliman, S.; Luabeya, A.K.K.; Geldenhuy, S.H.; Tameris, M.; Hoff, S.T.; Shi, Z.; Tait, D.; Kromann, I.; Ruhwald, M.; Rutkowski, K.T.; et al. Dose Optimization of H56:IC31 Vaccine for Tuberculosis-Endemic Populations. A Double-Blind, Placebo-controlled, Dose-Selection Trial. Am. J. Respir. Crit. Care Med. 2019, 199, 220-231. [CrossRef]

33. Bekker, L.G.; Dintwe, O.; Fiore-Gartland, A.; Middelkoop, K.; Hutter, J.; Williams, A.; Randhawa, A.K.; Ruhwald, M.; Kromann, I.; Andersen, P.L.; et al. A phase $1 \mathrm{~b}$ randomized study of the safety and immunological responses to vaccination with H4:IC31, H56:IC31, and BCG revaccination in Mycobacterium tuberculosis-uninfected adolescents in Cape Town, South Africa. EClinicalMedicine 2020, 21, 100313. [CrossRef]

34. Norrby, M.; Vesikari, T.; Lindqvist, L.; Maeurer, M.; Ahmed, R.; Mahdavifar, S.; Bennett, S.; McClain, J.B.; Shepherd, B.M.; Li, D.; et al. Safety and immunogenicity of the novel H4:IC31 tuberculosis vaccine candidate in BCG-vaccinated adults: Two phase I dose escalation trials. Vaccine 2017, 35, 1652-1661. [CrossRef] 
35. Nemes, E.; Geldenhuys, H.; Rozot, V.; Rutkowski, K.T.; Ratangee, F.; Bilek, N.; Mabwe, S.; Makhethe, L.; Erasmus, M.; Toefy, A.; et al. Prevention of M. tuberculosis Infection with H4:IC31 Vaccine or BCG Revaccination. N. Engl. J. Med. 2018, 379, 138-149. [CrossRef]

36. Whitlow, E.; Mustafa, A.S.; Hanif, S.N.M. An Overview of the Development of New Vaccines for Tuberculosis. Vaccines 2020, 8 , 586. [CrossRef]

37. Ullah, I.; Bibi, S.; Ul Haq, I.; Safia; Ullah, K.; Ge, L.; Shi, X.; Bin, M.; Niu, H.; Tian, J.; et al. The Systematic Review and Meta-Analysis on the Immunogenicity and Safety of the Tuberculosis Subunit Vaccines M72/AS01 $\mathrm{E}$ and MVA85A. Front. Immunol. 2020, 11, 1806. [CrossRef] [PubMed]

38. Weerasuriya, C.K.; Clark, R.A.; White, R.G.; Harris, R.C. New tuberculosis vaccines: Advances in clinical development and modelling. J. Intern. Med. 2020, 288, 661-681. [CrossRef]

39. Safar, H.A.; Mustafa, A.S.; McHugh, T.D. COVID-19 vaccine development: What lessons can we learn from TB? Ann. Clin. Microbiol. Antimicrob. 2020, 19, 56. [CrossRef]

40. Vasina, D.V.; Kleymenov, D.A.; Manuylov, V.A.; Mazunina, E.P.; Koptev, E.Y.; Tukhovskaya, E.A.; Murashev, A.N.; Gintsburg, A.L.; Gushchin, V.A.; Tkachuk, A.P. First-In-Human Trials of GamTBvac, a Recombinant Subunit Tuberculosis Vaccine Candidate: Safety and Immunogenicity Assessment. Vaccines 2019, 7, 166. [CrossRef] [PubMed]

41. Sivakumaran, D.; Blatner, G.; Bakken, R.; Hokey, D.; Ritz, C.; Jenum, S.; Grewal, H.M.S. A 2-Dose AERAS-402 Regimen Boosts $\mathrm{CD}^{+}$Polyfunctionality in HIV-Negative, BCG-Vaccinated Recipients. Front. Immunol. 2021, 12, 673532. [CrossRef]

42. Manjaly Thomas, Z.R.; Satti, I.; Marshall, J.L.; Harris, S.A.; Lopez Ramon, R.; Hamidi, A.; Minhinnick, A.; Riste, M.; Stockdale, L.; Lawrie, A.M.; et al. Alternate aerosol and systemic immunisation with a recombinant viral vector for tuberculosis, MVA85A: A phase I randomised controlled trial. PLoS Med. 2019, 16, e1002790. [CrossRef]

43. Wilkie, M.; Satti, I.; Minhinnick, A.; Harris, S.; Riste, M.; Ramon, R.L.; Sheehan, S.; Thomas, Z.M.; Wright, D.; Stockdale, L.; et al. A phase I trial evaluating the safety and immunogenicity of a candidate tuberculosis vaccination regimen, ChAdOx1 85A prime-MVA85A boost in healthy UK adults. Vaccine 2020, 38, 779-789. [CrossRef] [PubMed] 